\title{
Mastitis Acuta in a Pure Breed Cane Corso female. A Case Report
}

\author{
Iosif VASIU ${ }^{*}$, Alexandru Raul POP ${ }^{2}$, Flore Chirilă $\breve{3}^{3}$, Flaviu TĂBĂRAN ${ }^{4}$, Marian Taulescu4, Florinel \\ Gheorghe BRUDAȘC $\breve{A}^{1}$
}

${ }^{1}$ Department of Infectious Diseases, Faculty of Veterinary Medicine, University of Agricultural Science and Veterinary Medicine, Cluj-Napoca, Romania

${ }^{2}$ Department of Reproduction, Gynaecology and Obstetrics, Faculty of Veterinary Medicine, University of Agricultural Science and Veterinary Medicine, Cluj-Napoca,

${ }^{3}$ Department of Microbiology, Faculty of Veterinary Medicine, University of Agricultural Science and Veterinary Medicine, Cluj-Napoca, Romania

${ }^{4}$ Department of Anatomic Pathology, Necropsy and Forensic Medicine, Faculty of Veterinary Medicine, University of Agricultural Science and Veterinary Medicine, Cluj-Napoca, Romania

*corresponding author: iosif.vasiu@usamvcluj.ro

\begin{abstract}
Data regarding bitch mastitis is fairly scarce compared to the literature regarding ruminant mastitis. Neglecting clinical and subclinical cases of mastitis can be life threatening for both dam and puppies. The aim of this report is to present a case of Mastitis acuta complicated with a case of neonatal septicaemia in a Cane Corso (Canis lupus familiaris L.) pure breed female. Laboratory assays showed a milk $\mathrm{pH}$ value of 7.5, milk cytology revealed the presence of segmented neutrophils, while foamy cells, phagocytosis and highly pathogenic bacteria (i.e. Escherichia coli and Pseudomonas aeruginosa) were isolated from milk and puppy. To the author's knowledge, this is the first case of bitch mastitis linked to neonatal septicaemia with mixed E. coli and P. aeruginosa infection.
\end{abstract}

Keywords: Bitch, cytology, Escherichia coli, mastitis, Pseudomonas aeruginosa, septicaemia.

\section{INTRODUCTION}

In Mastits acuta episodes, both local (hot, red, engorged, painful mammary glands) and systemic, (depression, lethargy, anorexia, fever, failure to care for pups) signs of illness may be found (Johnston et al., 2001). Local signs of illness may vary from classical signs of inflammation to gangrene lesions (Trasch and Wehrend, 2008).

So far, bacterial infections are held responsible for bitch acute mammary gland infections. Proteus mirabilis (Lee et al., 2009), Staph. hyicus (Aráujo et al., 2011) and Staph. intermedius (Ververidis et al., 2007) have been reported to cause acute mammary infections.

Bitch vaginal microflora is thought to be one of the causes of neonatal infections in pups (Milani et al., 2012). From uterine infections (Martí, 2009) such as acute metritis (Fontaine et al., 2007) via the blood stream (Martí, 2009), bacteria can embolize during the postpartum period into the mammary glands (Fontaine et al., 2007).

Milk cytology is used to determine the mammary glands' health status (Olson and Olson, 1984; Sangha et al., 2010). Because milk antibiotic therapeutic levels must be reached whenever dealing with mammary gland infections, milk $\mathrm{pH}$ levels should always be considered before starting treatment (Martí, 2009).

Subclinical mastitis can lead to neonatal infections after milk intake, because feeding on the infected mammary glands can lead to septicaemia or fatal gastroenteritis (Sager and Remmers, 1990; 
Schäfer-Somi et al., 2003). The aim of this paper is to highlight the important role of early diagnose and treatment of mammary gland infections, in order to limit or even avoid neonatal mortality by describing a postpartum Mastitis acuta episode complicated with mortinatality in a Cane Corso breed.

\section{MATERIAL AND METHODES}

A $45 \mathrm{~kg}$, 5-year-old multiparous, Cane Corso female, gave birth to thirteen pups, after a normal pregnancy, out of which 4 were stillborn. During the third week after whelping, the remaining puppies started to lose weight and one puppy died. The owner arrived at the hospital of the Veterinary Faculty at the University of Agricultural Science and Veterinary Medicine in Cluj-Napoca, with the dam and the dead puppy, a day after the pup died.

During the consult, the bitch presented inflamed, red, painful, engorged inguinal mammary glands that expressed a brown milk secretion. All other clinical parameters (i.e. temperature, respiration, heart rate) were within normal limits. After the consult, the bitch was diagnosed with Mastitis acuta. A 14-day course of amoxicillin/ clavulanic acid (15mg/kg b.w., per os, BID) (Novartis, Switzerland) antibiotic treatment was prescribed for the bitch, along with hot packs of water every 8 to $12 \mathrm{~h}$ on all the glands. The puppies were allowed to nurse until further notice, while keeping track of which pup had sucked from the clinically affected glands.

Before treatment, even thought the bitch continued to feed the litter, puppies showed weight loss. The puppy presented to the hospital showed before death (a night before consult), progressive weakness, ataxia and generalized tremor.

For complete blood count (CBC), from the dam, a blood sample was collected from the vena cefalica in an EDTA tube (Vacutest Kimas r.l., Piove di Sacco PD, Italia). Complete blood count was determined with Abacus Junior Vet analyzer (Diatron Messtechnik, Budapest, Hungary) whilst differential blood count was counted on blood film stained with Dia-Quick Panoptic dye kit (Reag-Fix Panoptic, ReagensKft., Budapest Hungary).

From the inguinal mammary glands, two separate milk samples were collected into sterile tubes (Nunc TM, Waltham, USA), by manual expression (the first milk drop was discarded), using sterile gloves, after a thorough disinfection of the inguinal mammary glands using $70 \%$ alcohol (Martín et al, 2010). The samples were kept on ice and immediately rushed to the Infectious Disease Department for microbiology assays.

Milk samples were collected for, microbiology, $\mathrm{pH}$ and cytology evaluation. The other mammary glands as well as milk secretions, posed no overt signs of illness. The non-surviving puppy's necropsy and milk sensitivity were performed pro bono.

Standard microbiological tests were used to isolate and identify the bacteria species (SchäferSomi et al., 2003). Biochemical assays were performed using the commercial API $20 \mathrm{NE}$ and API 20 E systems (BioMérieux, Marcy l'Etoile, France), according to the manufacturer's instructions (Vela et al., 2006). For susceptibility, antimicrobial disc diffusion testing was performed. The following antimicrobial discs were used: $25 \mu \mathrm{g}$ trimethoprimsulfamethoxazole, $5 \mu \mathrm{g}$ marbofloxacin, $10 \mu \mathrm{g}$ gentamicin, $30 \mu \mathrm{g}$ amoxicillin-clavulanate, $30 \mu \mathrm{g}$ amoxicillin, $30 \mu \mathrm{g}$ kanamycin, $21 \mu \mathrm{g}$ enrofloxacin and $26 \mu \mathrm{g}$ cefquinome (Wedley et al., 2011).

The $\mathrm{pH}$ values were measured from the obtained milk samples $(\mathrm{N}=2)$ with indicator strips (E. Merk, Darmstadt, Germany), (Delucchi et al., 2008) by using one drop of milk secretion collected with a sterile bacteriological loop.

For milk cytology interpretation, one drop of milk was used to prepare smears from lacto sediments obtained after a 10 minute centrifugation at $2500 \mathrm{rpm}$. The smears were stained by using the May-Grünwald Giemsa (MGG), (E. Merk, Darmstadt, Germany) technique, followed by optic microscopic interpretation (Ververidis et al., 2007).

The puppy's necropsy showed acute bilateral greenish purulent ventriculitis, and Toxocara canis infestation. Under aseptic conditions, samples from the purulent exudates were collected and submitted to the above mentioned laboratory for further microbiology test.

\section{RESULTS AND DISCUSSIONS}

Haematology evaluation showed presence of normal range white blood cells with normocytic normochromic anemia, lymphopenia and reactive thrombocytosis.

Pseudomonas aeruginosa and E. coli were isolated from bitch milk. The susceptibility test 


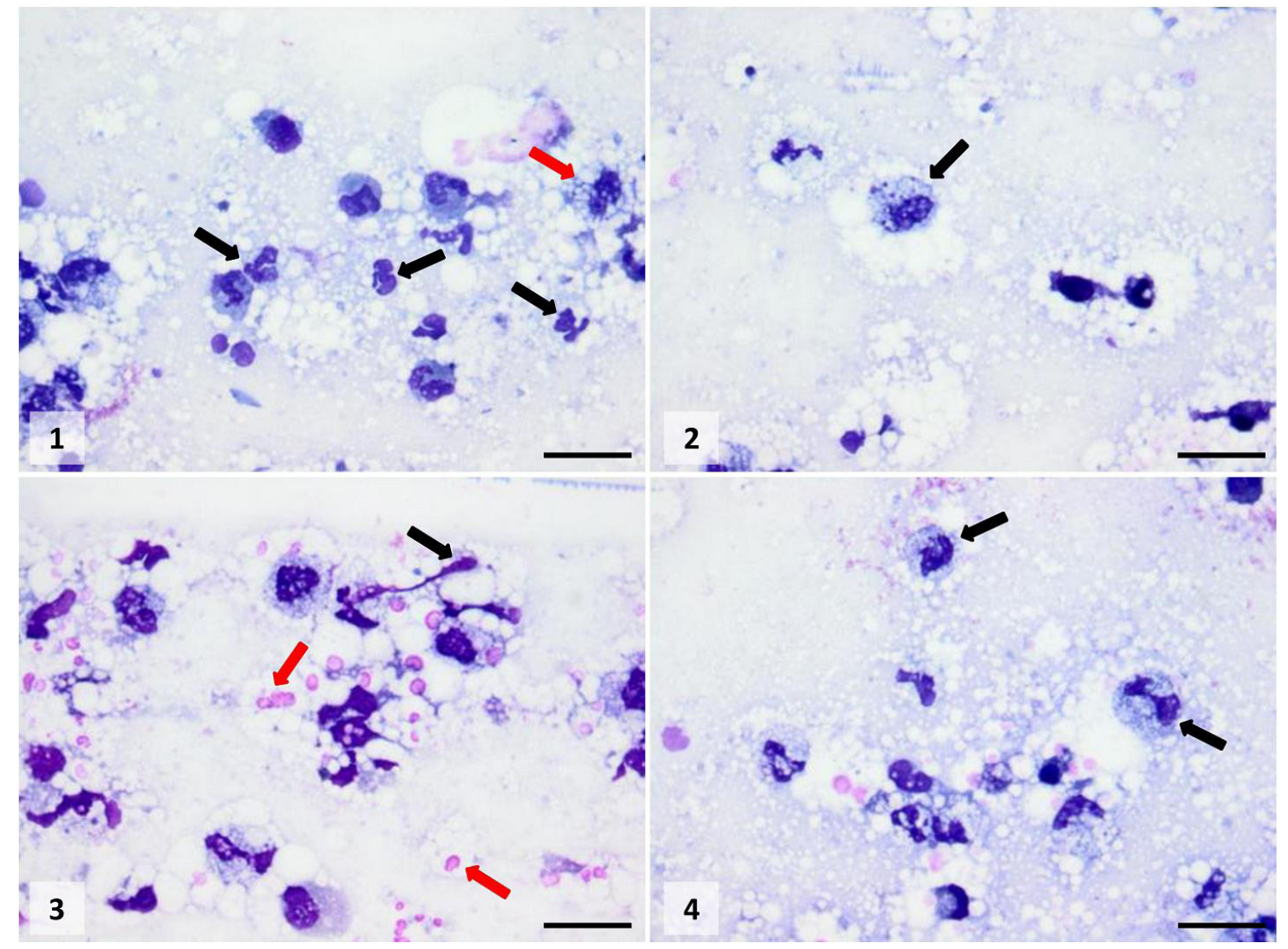

Fig. 1. Presence of multiple neutrophils (black arrows), and a foamy cell (red arrow) indicating an acute inflammation process in a milk smear of a postpartum lactating bitch inguinal mammary gland (MGG, x100).

Fig. 2. Presence of engulfed bacteria in an activated macrophage in a milk smear of a postpartum lactating bitch inguinal mammary gland (black arrow) (MGG, x100).

Fig. 3. Presence of erythrocytes (red arrows), evidence of blood traces in the milk, degenerated neutrophils (black arrow), and foamy cells in a milk smear of a postpartum lactating bitch inguinal mammary gland (MGG, x 100).

Fig. 4. Presence of foamy cells (black arrows), erythrocytes, and neutrophils in a milk smear of a postpartum lactating bitch inguinal mammary gland (MGG, x100).

showed resistance only to trimethoprim-sulfamethoxazole, while showing a marked sensitivity to all the other tested drugs, especially to amoxicillin/clavulanic acid. The bitch antibiotic treatment was carried out with the same drug.

Milk pH for the left and the right mammary inguinal glands was 7 and 7.5 respectively. Milk cytology showed the presence of a large number of degenerate neutrophils (Fig. 1 and Fig. 3), erythrocytes (Fig. 2 and Fig. 4), foamy cells (Fig. 3 ), and activated macrophages with phagocytosis (Fig. 2), in both glands. The laboratory findings were consistent with the clinical signs.

Necropsy and microbiological tests confirmed that the puppy died from systemic infection with central nervous system and lung involvement of
E. coli and P. aeruginosa mixed infection, which might have been transferred from the milk to the puppy.

Unfortunately, because the owner ceased to give any more feed-back, we were not able to keep track of the dam`s health status.

Milk cytology is an important criterion in establishing the mastitis diagnosis in bitch. Presence of phagocytosis, degenerated neutrophils, macrophage-foamy cells, bacteria and erythrocytes on milk smears is consistent with a positive diagnostic for Mastitis acuta (Olson and Olson, 1984; Manuali et al., 2004; Sangha et al., 2011).

However, there are few reports were $\mathrm{pH}$ assays are taken into consideration when diagnosing a 
mammary gland inflammation episode (Hasegawa et al., 1993; Dziecioł et al., 2006; Akhtardanesh et al., 2013). Dziecioł et al., (2006) findings suggest that mastitis milk has an alkaline mean value of 7 , while pseudocyesis scenarios present a mean $\mathrm{pH}$ value of 6.7 (Dziecioł et al., 2006).

It is of great importance to keep in mind the bacteriological findings of both dam and pups when trying to establish the cause of death in neonatal mortality cases. In one study, from bitches presenting puppies with neonatal mortality, E. coli was isolated in pure culture, in $41.7 \%$ of bitch`s vagina (Bjurström, 1993).

An important source for infections in newborns (Vela et al., 2006) are potentially pathogenic bacteria such as Staph. pseudintermedius, Staph. aureus, Streptococcus canis and E. coli, that are considered to be part of the normal flora in dam`s vagina and milk (Milani et al., 2012). However, bitch subclinical mastitis has also been incriminated to cause septicaemia in puppies (Schäfer-Somi et al., 2003). Streptococcus dysgalactiae subsp. dysgalactiae was isolated from two Great Dane puppies that died from neonatal septicaemia (Vela et al., 2006). In the case described here, presence of $E$. coli and P. aeruginosa in both bitch milk and pup, highlights the important role of milk pathogens in neonatal septicaemia.

The present case suggests that $E$. coli and $P$. aeruginosa mixed infection should be considered as differential diagnosis in the cases of Mastitis acuta in bitch. Sanitary conditions and close monitoring of neonates are very important factors in the prophylactic management of the postpartum dam. Nosocomial infections or transmission of dog bacterial pathogens to owners have also been reported (Münnich and Lübke, 2004; Rota et al., 2011).

This report presents a comprehensive summary of the clinical signs and diagnostic strategy in a case of Mastitis acuta due to E. coli and $P$. aeruginosa co-infection in bitch, followed by mammary transmitted infection and mortinatality in pups. To limit pathogen transmission from bitch to newborn through milk and to prevent neonatal mortality, the use of laboratory assays (i.e. pH, milk cytology and microbiology) can be of great benefit to breeders worldwide.
Acknowledgement: The warmest of thanks to Tressa Rebek-Nagy for reviewing this manuscript and for helping with English grammar and spelling.

\section{REFERENCES}

1. Akhtardanesh B, Hejazi SM, Kheirandish R, Oloumi MM, Moghadaszadeh M, Hosseini HS (2013). Mastitis obliterans in a diabetic dog: bacteriological and pathological findings. Onl J Vet Res 17(7):396-401.

2. Aráujo MR, Preis IS, França SA, Paniago JG, Costa MC, Oliveira JSV, Ecco R (2011). Mastitis accompanied by lymphadenitis in a dog caused by Staphylococcus hyicus. Braz J Vet Pathol 4(1):52-57.

3. Bjurström L (1993). Aerobic bacteria occurring in the vagina of bitches with reproductive disorder. Acta vet scand 34:29-34.

4. Delucchi L, Fraga M, Perelmuter K, Cidade E, Zunino P (2008). Bactériese lactiques vaginales chez des chiennes en santé et maladies et evaluation in vitro de l'activité probiotiqued isolats sélectionnés, [Vaginal lactic acid bacteria in healthy and ill bitches and evaluation of in vitro probiotic activity of selected isolates]. Can vet J 49:991-994.

5. Dziecioł M, Stefaniak T, Twardoń J., Kozdrowski R (2006). Wybranewskanikimleka i krwisukzezdrowym i chorymgruczolemsutkowym, [Chosen parameters of the milk and blood of bitches with healthy mammary glands and those suffering from mastitis]. Med Weter 62:59-61.

6. Fontaine E, Tanneur ML, Josien A (2007). Mammite gangreneuse chez la chienne reproductrice. Le Point Vétérinaire 276:25-29.

7. Hasegawa T, Fuji M, Fukada T, Tduji C, Fujita T, Goto Y, Shinjo T, Ogawa H (1993). Platelet abnormalities in a dog suffering from gangrenous mastitis by Staphylococcus aureus infection. J Vet Med Sci 55:169-171.

8. Johnston DS, Root Kustritz VM, Olson NSP (2001). Periparturient Disorders in the Bitch. In: Canine and Feline Theriogenology, 1st ed, WB Saunders Co, Philadelphia pp. 129-145.

9. Lee J-W, Chu K-S, Kwak K-H, Ko W-S, Song H-J (2009). Mastitis with Proteus mirabilis in Brittany Spaniel, a case. Korean J vet Serv 32(2):215-218.

10. Manuali E, Eleni C, Giovannini P, Costarelli S, Ciorba A (2004). Unusual finding in a nipple discharge of a female dog: Dirofilariasis of the breast. Diagn Cytopathol 32(2):108-109.

11. Martí AJ (2009). Clinical aspects of mammary disease in the bitch and queen. In: Proceedings of the Southern European Veterinary Conference -SEVC- , Barcelona, Spain.

12. Martín R, Olivares M, Pérez M, Xaus J, Torre C, Fernández $\mathrm{L}$ (2010). Identification and evaluation of the probiotic potential of lactobacilli isolated from canine milk. Vet J 185:193-198.

13. Milani C, Corró M, Drigo M, Rota A (2012). Antimicrobial resistance in bacteria from breeding dogs housed in kennels with differing neonatal mortality and use of antibiotics. Theriogenology 78:1321-1328. 
14. Münnich A, Lübke-Becker A (2004). Escherichia coli infections in newborn puppies - clinical and epidemiological investigations. Theriogenology 62:562575.

15. Olson PN, Olson AL (1984). Cytologyc evaluation of canine milk. Vet Med-US. 641-644.

16. Rota A, Milani C, Drigo I, Drigo M, Corró M (2011). Isolation of methicillin-resistant Staphyloccocus pseudintermedius from breeding dogs. Theriogenology 75:115-121.

17. Sager M, Remmers C, (1990). Perinatal mortality in dogs. Clinical, bacteriological and pathological studies (in German). Tierarztl Prax 18:415-9.

18. Sangha S, Singh A, Sood KN, Gupta K (2010). Specificity and sensitivity of cytological techniques for rapid diagnosis of neoplastic and non-neoplastic lesions of canine mammary gland. Braz J Vet Pathol 4(1):13-22.

19. Schäfer-Somi S, Spergser J, Breitenfellner J, Aurich JE (2003). Bacteriological status of canine milk and septicaemia in neonatal puppies - a retrospective study. J Vet Med B (50):343-346.
20. Trasch K, Wehrend A (2008). Clinical, Klinische, sonographische und mikrobiologische Untersuchungen bei Hündinnen mit acuter Mastitis [Ultrasonographical and microbiological investigations in inflamed canine mammary glands]. Tierärztl Prax 36(K):191-199.

21. Vela IA, Falsen E, Simarro I, Rollan E, Collins DM, Domínguez L, Fernandez-Garayzabal F (2006). Neonatal mortality in puppies due to bacteriemia by Streptococcus dysagalactiae subsp. dysagalactiae. J Clin Microbiol 44(2): 666-668.

22. Ververidis HN, Mavrogianni VS, Fragkou IA, Orfanou DC, Gougoulis DA, Tzivara A, Gouletsou PG, Athanasiou L, Boscos CM, Fthenakis GC (2007). Experimental staphylococcal mastitis in bitches: Clinical, bacteriological, cytological, haematological, and pathological features. Vet Microbiol 124:95-106.

23. Wedley AL, Maddox TW, Westgarth C, Coyne KP, Pinchbeck GL, Williams NJ, Dawson S (2011). Prevalence of antimicrobial-resistant Escherichis coli in dogs in a cross-sectional, community-based study. Vet Rec 268:354. 